\title{
Extending ONTAgri with Service-Oriented Architecture towards Precision Farming Application
}

\author{
Muhammad Fahad ${ }^{1,2, *(\mathbb{D})}$, Tariq Javid ${ }^{1, *(\mathbb{D}}$, Hira Beenish ${ }^{2} \mathbb{D}$, Adnan Ahmed Siddiqui ${ }^{1}\left(\mathbb{D}\right.$ and Ghufran Ahmed ${ }^{3}(\mathbb{D}$ \\ 1 Faculty of Engineering Sciences \& Technology, Hamdard University, Karachi 74600, Pakistan; \\ adnan.siddiqui@hamdard.edu.pk \\ 2 College of Computing and Information Science, Pakistan Air Force, Karachi Institute of Economics and \\ Technology, Karachi 75190, Pakistan; hira@pafkiet.edu.pk \\ 3 School of Computing, National University of Computer and Engineering Science (FAST-NUCES), \\ Karachi 75030, Pakistan; ghufran.ahmed@nu.edu.pk \\ * Correspondence: mfahad@pafkiet.edu.pk or muh.fahad@hotmail.com (M.F.); \\ tariq.javid@hamdard.edu.pk (T.J.); Tel.: +92-345-318-4603 (M.F.)
}

Citation: Fahad, M.; Javid, T.; Beenish, H.; Siddiqui, A.A.; Ahmed, G. Extending ONTAgri with Service-Oriented Architecture towards Precision Farming Application. Sustainability 2021, 13, 9801. https://doi.org/10.3390/ su13179801

Academic Editor: Andrea Colanton

Received: 5 July 2021

Accepted: 26 August 2021

Published: 31 August 2021

Publisher's Note: MDPI stays neutral with regard to jurisdictional claims in published maps and institutional affiliations.

Copyright: (c) 2021 by the authors. Licensee MDPI, Basel, Switzerland. This article is an open access article distributed under the terms and conditions of the Creative Commons Attribution (CC BY) license (https:// creativecommons.org/licenses/by/ $4.0 /)$.

\begin{abstract}
The computer science perspective of ontology refers to ontology as a technology, however, with a different perspective in terms of interrogations and concentrations to construct engineering models of reality. Agriculture-centered architectures are among rich sources of knowledge that are developed, preserved, and released for farmers and agro professionals. Many researchers have developed different variants of existing ontology-based information systems. These systems are primarily picked agriculture-related ontological strategies based on activities such as crops, weeds, implantation, irrigation, and planting, to name a few. By considering the limitations on agricultural resources in the ONTAgri scenario, in this paper, an extension of ontology is proposed. The extended ONTAgri is a service-oriented architecture that connects precision farming with both local and global decision-making methods. These decision-making methods are connected with the Internet of Things systems in parallel for the input processing of system ontology. The proposed architecture fulfills the requirements of Agriculture 4.0. The significance of the proposed approach aiming to solve a multitude of agricultural problems being faced by the farmers is successfully demonstrated through SPARQL queries.
\end{abstract}

Keywords: ontology; service-oriented architecture; knowledgebase; precision agriculture; internet of things; context awareness precision farming; context-aware services; agriculture ontology

\section{Introduction}

Ontology engineering in computer sciences and information systems refers to modeling domain knowledge for applications development. The ontologies are widely adopted in all major disciplines, including the agriculture domain. An example is the application of ontology for precision farming. An agriculture ontology helps professionals, including farmers, to understand the various concepts in the domain and how to use them in a better way. The ontology application in the form of a decision support system ensures crop management through the implementation of precision farming practices.

The applications of agriculture ontologies use technology components in the form of sensors and actuators. These devices are used to acquire the data and implement desired operations. Agriculture 4.0 adds internet connectivity to transform these into IoT devices. Furthermore, more sensors of technical relevance are introduced for a wider scope. Agriculture 4.0 provides automation, digitalization with big data, and artificial intelligence, which plays a vital role in business efficiency, production of crops, pest control, and livestock management. These advancements require the ontologies to be scalable and have important characteristics of serviceability and context-awareness.

Context-awareness states that devices can both react and sense based on the environment. The devices have information about the environment. Based on environmental 
information, it takes decisions and acts accordingly. Context-aware systems are mainly implemented using three steps: (1) the system acquires context for processing and observes the situation from different sources such as sensors; (2) afterward, it understands and represents the context that will be matched with the context perceived in the first step; and (3) finally, it recognizes the context by eliciting actions according to the context. For example, the backlight of a phone when entering any dark place, temperature and humidity sensors, etc. are examples of context-awareness. All these sensors act accordingly to take environmental information from heterogeneous sources.

A review of existing agriculture ontologies reveals that there is a need to introduce new ontologies with the characteristics of scalability, context-awareness, and serviceability. This may be accomplished by extending an already available ontology. This work extends ONTAgri [1] to incorporate these features. As the decision support system is the desired application, the work incorporates the reasoning processes at both local and global levels [2].

This work proposes the ONTAgriX ontology by extending an earlier work ONTAgri ontology [1]. ONTAgri is a scalable and service-oriented ontology. The proposed ontology combines system and domain ontologies. The domain ontology has core and services. The system ontology is described as a combination of hardware and software. It includes sensors, timers, counters, interfaces, packets, actuators, and others. This ontology lacks context-awareness and described the precision farming application only.

The ONTAgriX ontology extends ONTAgri ontology through the inclusion of the IoT subdomain and the reasoning process. The IoT subdomain includes internet-enabled devices, for example, sensors and actuators. IoT plays a major role in changing human life from traditional life to digital life. Smart mirror, smart city, smart vehicles, smart home, smart industries, autonomous transportation systems, smart curtain systems, smart drones, robots in restaurants, smart agriculture, and smart pest control management systems are a few examples of IoT transformations. Nowadays, IoT becomes an important part of our life in every domain. The reasoning process includes both local and global decision-making to compute the need of operations required to ensure crop management best practices for the precision farming application. A comparison with recent agriculture ontologies shows the significance of the proposed ontology in this research work.

The research accomplished in this work proposes extended ONTAgri (ONTAgriX) and implements it in Protégé [3], a well-known open-source platform. This platform provides an ontology editor and framework to build intelligent applications. Protégé is used to create the ontology model. This model is imported into the Apache Jena [4] Ontology application programming interface. Jena is an open-source framework for building semantic web and data link applications. The results are generated through the SPARQL query language.

The paper layout is as follows. The section Related Work presents an overview of the literature, its limitations, and identified research gaps. The proposed ontology is developed and simulated in Sections 3 and 4, respectively. Results are discussed with comparison in Section 5. Finally, the paper concludes in Section 6 with future work directions.

\section{Related Work}

An ontology refers to "an explicit specification of a conceptualization" [5]. The term ontology is borrowed from philosophy. It defines a set of primitives to model domain knowledge [6]. These primitives include classes, attributes, and relationships. Ontologies are widely adopted by various disciplines, ranging from biomedicine to finance, engineering, law, and cultural heritage [7]. Soon after the introduction of the term ontology in the 1980s, the work on agriculture ontologies also started.

Recent ontologies proposed in the research literature are [1,2,8-10]. A short description of these contributions is as follows. In [1], the author describes an architecture that is ontology-driven and may be used for precision farming applications; there are different entities working together-these entities often have their sensors and actuators and can function according to their role in the domain. The immediate decision process for these 
entities is through local decision making, and the final decision at a wider scale is through global decision making. In [2], the authors discussed a scalable service-oriented architecture (ONTAgri) based on several groups of concepts. Two major groups are domain ontology and system ontology. The domain is further divided into services and core parts of agriculture, e.g., irrigation, fertilization, etc.

Internet of Things (IoT) plays a major role in agriculture systems. These devices used in agriculture enhance the growth of crops. The major problem is simultaneously managing semantic data of all the phases of the agriculture system since they are not consistent all the time. In [8], the authors proposed the framework AgriOnt that may be used for smart agriculture. It has four areas: geographical ontology, business sub-domain, IoT-based sub-domain, and agriculture-based sub-domain. In [9], authors proposed a framework that matches evaluation approaches that are gold-standard, application-based, criteria-based, and data-driven to different ontology purposes that share vocabularies and integrate data, system interoperability, knowledge search and exploration, and decision support. In [10], the authors developed SAAONT, which is specifically focused on the farmers of the Saudi Arabia region. Previous ontologies did not support the required level of knowledge to farmers. During the development of ontology, different phases are used for the structure implementation of SAAONT, which includes a selection of ontology, re-utilization of ontology, modeling, and architecture design. The system architecture of SAAONT ontology is based on knowledge base architecture which consists of four components, views, application and APIs, Ontology and Artificial intelligence, storage, and physical hardware. Views are used between the end-user and application for the representation of the knowledge base of SAAONT. Application and APIs' responsibility is to run queries and code. Ontology and Artificial intelligence use Protégé and ontology reasoner HermiT for knowledge base in the domain. Storage and physical hardware are used to save information from all components.

Despite a significant amount of works accomplished in the above-mentioned ontologies, there is still a need to solve the problem of scalability, context-awareness, and being service-oriented. It is possible to include the desired characteristics by extending a selected work and incorporating selected features from others. In [1], authors described architecture that only works on plants' ontology, specifically, plants' core ontology and plants' higher ontology. In [2], context-awareness in ONTAgri is the main limitation that is missing, and it can be implemented with features of being service-oriented and scalable. In [8], the author proposed a framework, but that framework has the limitation of context-awareness, scalability, and service-oriented architecture. In [9], the authors only work on pest-ontology and apply evaluation methods discussed above. In future research, it can be implemented on other agriculture ontologies. In [10], authors only targeted Saudi Arabia and created ontology for the Arabic region; there are several ontologies in different languages, but recognition of the Arabic language is not common among farmers around the world, so this ontology is limited to the Arabic region only.

Existing approaches have minimum capability to overcome the constraints that are discussed above and do not have all features, e.g., scalability, service-oriented, and contextawareness. A few researchers implemented one or two approaches but not all approaches are used in any research. Some research works, related to precession farming, IoT, serviceoriented, core agriculture, and ontology, are discussed below.

In [11], the authors proposed an architecture named Rule Engine and Complex Event Processor. This architecture allows the dynamic processing of events in terms of precision farming and IoT. The Rule Engine and Event Processor are used to developing this architecture. Finally, the gathering data flow component is used; it obtains data from different platforms and communicates with sensors and actuators or other databases to obtain information and expected production of crops. In [12], information is collected related to the agriculture environment and soil from the rural area within a diameter of 17 kilometers. By using a control unit developed from sensors and actuators, investigation 
of communication performance is completed by obtaining information from soil surface temperature and soil moisture.

In [13], the authors introduced a cloud-based framework for adaptive, responsive, and service-oriented Internet of Things integrated models. The introduced framework produces context-aware middleware solutions. The proposed framework contains the functionality of precision farming with three cloud-based components, namely, social network, service, and context-aware middleware. In [14], authors used deep learning predictors for prediction and better performance of weather data using IoT in precision farming. A sequential twolevel decomposition structure is used to decompose weather data into four components, each component trained via a gated recurrent unit as a sub-predictor. The results of all components are combined to obtain prediction results. Decomposition, prediction, and combination are three steps of the model.

In [15], the authors proposed an approach for sensor measurement values by linking site-specific parameters to crop-specific trait ontologies. The main feature of the proposed approach is data integration for syntactic and semantic interoperability. Utilization of APIs and web services in syntactic interoperability of gadgets information in the agriculture domain is a key part of the research. An open data platform is developed to evaluate the proposed approach. Four layers are presented in the proposed approach, namely, processing, web services, semantic interoperability, and exportation. In [16], the author tries to find the best WSN technologies for precision farming by investigating different agriculture scenarios. Three wireless networks are used in this work for precision framing, namely, NB-IoT, LoRa, and ZigBee. Communication time and power consumption are compared by the corresponding test of these WSNs. A wireless sensor network is an environment with ' $n$ ' number of nodes. Every node has a battery, sensor, transceiver, and microcontroller with a circuit. Every node in the network is connected to each other and used for data collection.

In [17], the authors discussed the communication mechanism for IOUT after reviewing communication architecture. Different communication mechanisms are discussed in this article. The most important part of the communication mechanism is sensing that improves the production of crops and efficiency in agricultural processes. However, wireless connectivity is also presented in terms of in-field communications where different sensors are used with respect to their power consumption, time efficiency, etc., and implementation of cloud and big data in precision farming as well. IOUT are autonomous devices placed underground partly or completely; they collect information of soil, plants, etc., and send it to farmers for decision-making by real-time sensing and monitoring. IOUT facilitates integration of machineries, underground sensors, and agriculture irrigation systems. In [18], the author constructs the ontology OntoAgroHidro, which represents knowledge on agriculture activities and climatic changes on water resources. Interoperability issues are also part of the research work. Different steps are highlighted to resolve the issues.

Recommendation, decision, and semantic search systems are also developed to overcome the issue of ontology. In [19], the authors proposed the recommendation system based on an ontology model to describe the outbreaks that pests produce to crops and the approved ways to treat and facilitate them. Pests, crops, and their treatment ontologies (PCT-O) are also discussed in this research work, which is an extension of the disease triangle.

In [20], the authors represent a method that is based on crop cultivation standard (CCS) combined with task ontology and domain ontology. The information comprises static information that is directed towards domain ontology, e.g., seeds, soils, and machines used in agricultural processes. Task ontology contains information on plant processes, e.g., soil and seed selection, irrigation, and fertilization. In [21], authors developed an ontology and apply a semantic search method on it, such as the ontology of knowledge regarding the cropping and production of longan fruit for the purpose of enhancing fruit quality and growing quality longan fruit suitable for the international market. 
Some novel approaches and solutions for wireless sensor networks are also discussed in [22], which are based on service-oriented middleware and service-oriented architecture. The goals and challenges of the middleware architecture of WSNs, namely, scalability, heterogeneity, data aggregation, QoS, managing battery power, security, and fault tolerance, are also discussed in detail. According to [23], the study of precision farming states that it is useful for the economic support for small to medium farms. It is going to be the next big thing in the agriculture industry because it works on precision, it can maximize the growth of the crops, and people who are using this technology obtain the best outcome. This does not only enhance the business and productivity of farmers but also avoids crop wastage due to imperfections from the manual process.

In [24], the authors present how precision farming is solving problems by increasing crop growth and saving time as well as cost-efficiency. Decision support systems (DSS) are defined as core concepts to optimize an agricultural model related to crop growth. It can use many smart devices such as the Internet of Things (IoT) to obtain the raw data from the plant's behavior. For example, a farmer obtaining bad behavior through sensor technology using a smartphone, and alarms, e.g., if the weather is bad, then the farmer will be notified by the behavior of plants; the issue can be managed accordingly to prevent any damage or loss.

In the above-mentioned related work, a few researchers developed ontologies, and some of them developed recommendation systems, presented case studies, and designed models and frameworks. Service-oriented, scalable, and context-aware are the main concerns of this research which are not presented by any researcher. ONTAgri is serviceoriented and scalable, but context-awareness is a limitation of the research. To overcome this limitation, a new model is proposed in the next section; the new model has the capability to take environmental information of agriculture-related issues, e.g., pesticides, soil, fertilization, and irrigation, etc. The new model utilizes heterogeneous information about agriculture issues in the region. It presents this information along with the available actions based on local and global decision making processes. This is accomplished through a query configured to trigger automatically or interactively. The end user selects one or more actions. The model implements end user selected actions through actuators. Table 1 is also presented a literature matrix having the implementation type, name, limitation, and purpose of the research.

Table 1. Literature matrix with implementation type, name, limitation, and purpose.

\begin{tabular}{|c|c|c|c|c|}
\hline Reference & $\begin{array}{l}\text { Implementation } \\
\text { Type }\end{array}$ & $\begin{array}{l}\text { Implementation } \\
\text { Name }\end{array}$ & Limitation & Purpose \\
\hline [1] & Model & ONTAgri & Context-awareness & Solution for precision farming \\
\hline [2] & Architecture & Plants Ontology & $\begin{array}{c}\text { Ontology alignment with } \\
\text { other systems }\end{array}$ & $\begin{array}{l}\text { Solution for precision } \\
\text { agriculture application }\end{array}$ \\
\hline [7] & Case study & - & - & $\begin{array}{l}\text { Overview of unsolved issues } \\
\text { and opportunities }\end{array}$ \\
\hline [8] & Model & AgriOnt & $\begin{array}{l}\text { Larger and precise } \\
\text { knowledge maps }\end{array}$ & Smart agriculture \\
\hline [9] & Framework & - & $\begin{array}{l}\text { Hierarchy level evaluation } \\
\text { pest control ontology }\end{array}$ & $\begin{array}{l}\text { Selection of suitable } \\
\text { evaluation methods }\end{array}$ \\
\hline [10] & Model & SAAONT & $\begin{array}{c}\text { Capability of operating } \\
\text { complex areas and } \\
\text { handling of a large data set }\end{array}$ & $\begin{array}{c}\text { Smarter agriculture environment and } \\
\text { standardize agriculture terminology } \\
\text { in Arabic }\end{array}$ \\
\hline [11] & Architecture & RECEP & $\begin{array}{l}\text { Automated event } \\
\text { processing }\end{array}$ & $\begin{array}{c}\text { IoT and precision agriculture with } \\
\text { dynamic processing of } \\
\text { events generation }\end{array}$ \\
\hline
\end{tabular}


Table 1. Cont.

\begin{tabular}{|c|c|c|c|c|}
\hline Reference & $\begin{array}{l}\text { Implementation } \\
\text { Type }\end{array}$ & $\begin{array}{l}\text { Implementation } \\
\text { Name }\end{array}$ & Limitation & Purpose \\
\hline [12] & $\begin{array}{l}\text { Context-aware } \\
\text { platform }\end{array}$ & - & $\begin{array}{l}\text { Context-awareness and } \\
\text { artificial intelligence } \\
\text { relationship with RNN }\end{array}$ & $\begin{array}{c}\text { Communication performance of soil } \\
\text { moisture and soil } \\
\text { temperature investigation }\end{array}$ \\
\hline [13] & Framework & - & $\begin{array}{l}\text { Evaluation of model } \\
\text { through integration } \\
\text { multiple PF environments }\end{array}$ & $\begin{array}{l}\text { Context-aware operation with } \\
\text { cloud-based distributed } \\
\text { middleware component }\end{array}$ \\
\hline [14] & $\begin{array}{l}\text { Prediction } \\
\text { framework }\end{array}$ & - & - & $\begin{array}{l}\text { Increase the prediction performance of } \\
\text { weather data using IoT and precision } \\
\text { agriculture systems }\end{array}$ \\
\hline [15] & $\begin{array}{l}\text { Proposed } \\
\text { approach }\end{array}$ & - & $\begin{array}{c}\text { Implementation of } \\
\text { interoperability layers of } \\
\text { open data platforms. E.g., } \\
\text { use of API from } \\
\text { mobile-based application }\end{array}$ & $\begin{array}{l}\text { A data integration approach is } \\
\text { proposed to address crop-specific } \\
\text { trait ontologies }\end{array}$ \\
\hline [16] & $\begin{array}{l}\text { Literature/case } \\
\text { study }\end{array}$ & - & $\begin{array}{l}\text { Area coverage with respect } \\
\text { to WSN technologies }\end{array}$ & $\begin{array}{l}\text { To find feasible and suitable WSN for } \\
\text { precision agriculture }\end{array}$ \\
\hline [17] & $\begin{array}{c}\text { Literature re- } \\
\text { view/identification }\end{array}$ & - & - & $\begin{array}{l}\text { Communication mechanism of IOUT } \\
\text { is discussed }\end{array}$ \\
\hline [18] & Case study & - & $\begin{array}{l}\text { Issues of other models can } \\
\text { be represented, e.g., } \\
\text { 'Agrovoc' }\end{array}$ & $\begin{array}{l}\text { Describes the issue of OntoAgroHidro, } \\
\text { an ontology that represents } \\
\text { knowledge about climate changes and } \\
\text { impacts of agriculture activities }\end{array}$ \\
\hline [19] & $\begin{array}{l}\text { Recommendation } \\
\text { system }\end{array}$ & $\begin{array}{l}\text { Agriculture } \\
\text { recommendation } \\
\text { system }\end{array}$ & $\begin{array}{l}\text { Implementation can be } \\
\text { completed with data of } \\
\text { other countries }\end{array}$ & $\begin{array}{l}\text { Identification of pests and recommend } \\
\text { suitable treatment }\end{array}$ \\
\hline [20] & $\begin{array}{l}\text { Knowledge } \\
\text { representation }\end{array}$ & - & - & $\begin{array}{l}\text { Combine two ontologies and } \\
\text { implement knowledge management } \\
\text { for services of agriculture }\end{array}$ \\
\hline [21] & $\begin{array}{l}\text { Knowledge } \\
\text { service system }\end{array}$ & $\begin{array}{l}\text { Thai Longan } \\
\text { production } \\
\text { knowledge service } \\
\text { system }\end{array}$ & $\begin{array}{l}\text { Pre-production planning, } \\
\text { forecasting, problem } \\
\text { diagnosis tool }\end{array}$ & $\begin{array}{l}\text { Develop an ontology and apply } \\
\text { semantic search method to the } \\
\text { production of Longan fruit }\end{array}$ \\
\hline [22] & Survey & - & $\begin{array}{l}\text { Machine learning can also } \\
\text { be implemented with SOM }\end{array}$ & $\begin{array}{l}\text { It provides solution to Wireless sensor } \\
\text { network challenges that are based on } \\
\text { SOA and SOM }\end{array}$ \\
\hline [23] & Case study & - & - & $\begin{array}{c}\text { Study of precision farming states that } \\
\text { it is useful for the economic support } \\
\text { for small to medium farms }\end{array}$ \\
\hline [24] & Survey & - & - & $\begin{array}{l}\text { It shows the newest development } \\
\text { using ML, statistical inference, and } \\
\text { optimum control of precision farming }\end{array}$ \\
\hline
\end{tabular}

\section{Proposed ONTAgri Extension}

A new ontology, ONTAgriX, is proposed in this work by extending the ONTAgri [1] architecture. The ONTAgri is detailed in the Related Work section. Figures 1 and 2 are the model and ontology of ONTAgri, respectively. The foundational ONTAgri divided the ontology into system and domain sub-ontologies. Before the implementation of the proposed ontology, ONTAgri was implemented to understand the insight of the ontology. Table 2 is defining the structure of the proposed model. The proposed ontology consists 
of numerous eGadgets and eEntities. Examples are farms, plants, irrigation, fertilization, sensors, actuators, and more.

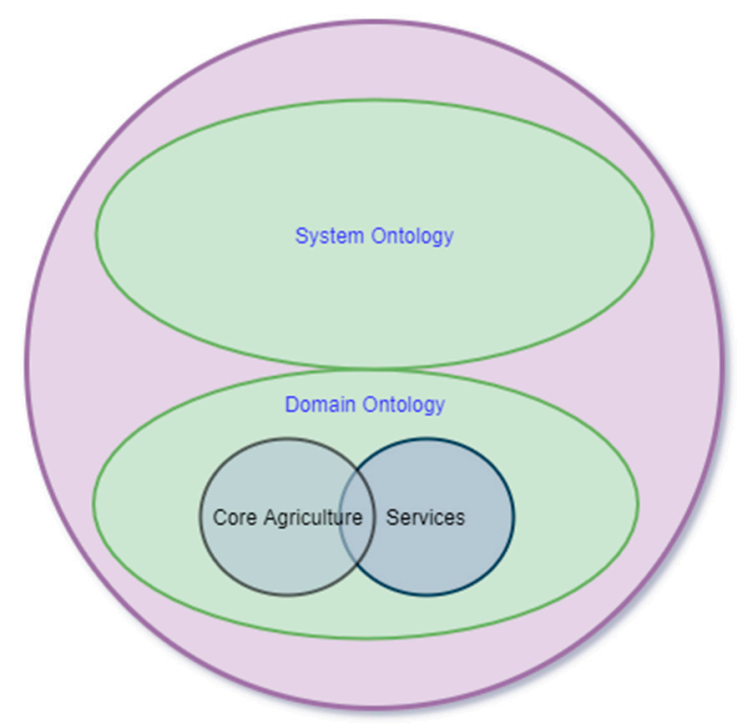

Figure 1. ONTAgri model [1].

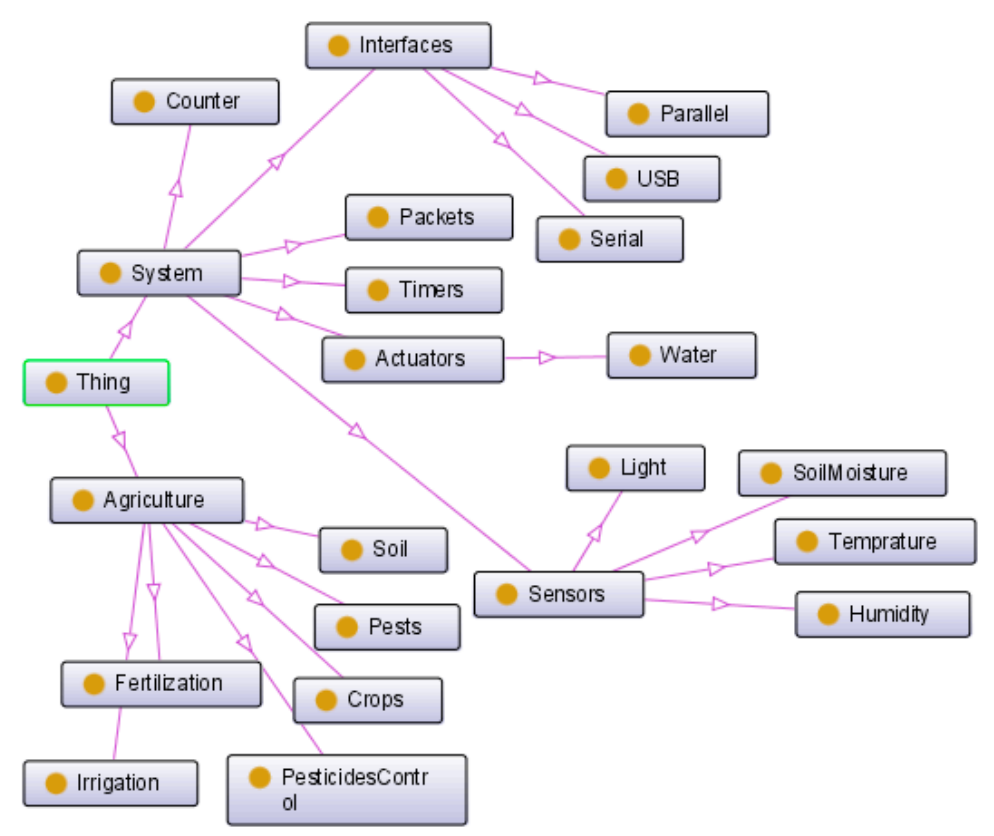

Figure 2. ONTAgri ontology [1] in Protégé.

In the ONTAgriX, many features are introduced in the system ontology. For example, a lamp as an eGadget is placed at an appropriate distance to the plants. Now, when the local decision-making analyzed the data acquired from the sensors that the plants are in a state of receiving an excessive amount of energy from the sunlight and lamp, then it sends the turn-off signal to the actuator for the lamp. The lamp is turned off to remove its contribution to the sunlight and to achieve the desired optimal state for the plants. A similar mechanism may adjust the lamp luminosity to exact control in a more precise manner. In this way, if the local decision-making responds positively to global decision making, it indicates to the farmer that the plants have exceeded the energy consumption threshold and the light in the form of a lamp for the plant should be turned off. 
Table 2. Defining structures of the proposed model.

\begin{tabular}{lll}
\hline Figure & Description & Remarks \\
\hline Figure 1 & Model of ONTAgri ontology & {$[1]$} \\
\hline Figure 2 & Implementation on Protégé & \\
\hline Figure 3 & Model of AgriOnt ontology & {$[8]$} \\
\hline Figure 4 & AgriOnt ontology & \\
\hline Figure 5 & Plant ontology & {$[2]$} \\
\hline Figure 6 & Model of ONTAgriX & Proposed \\
\hline Figure 7 & ONTAgriX model ontology & Proposed \\
\hline Figure 8 & ONTAgriX architecture & Proposed \\
\hline
\end{tabular}

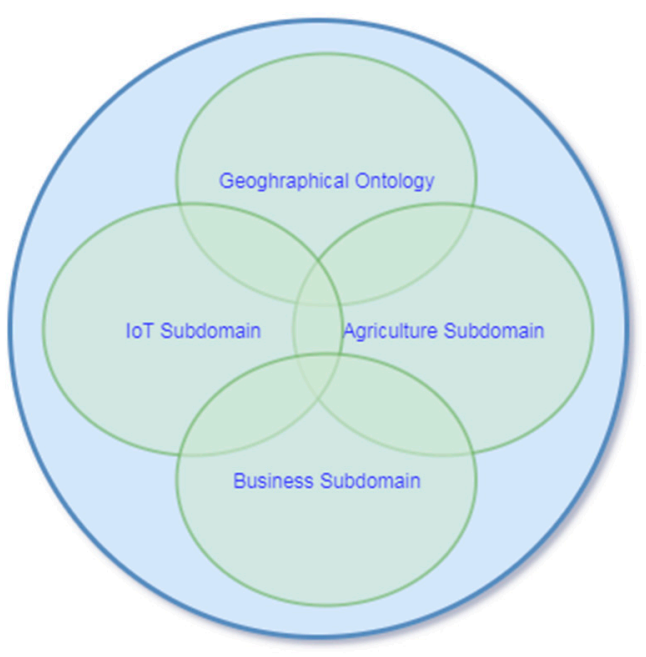

Figure 3. AgriOnt model [8].

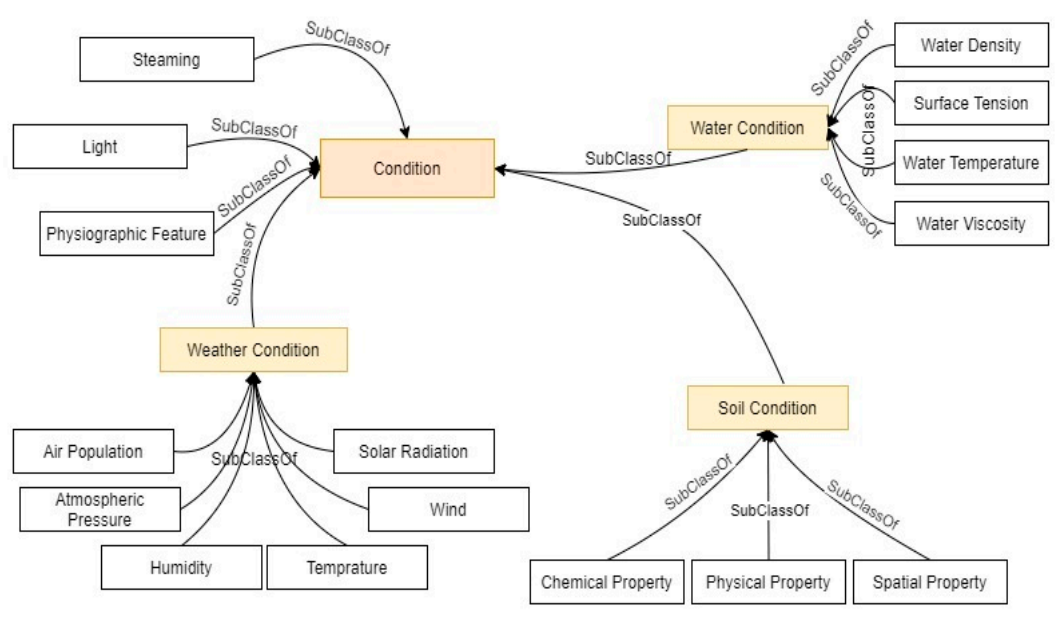

Figure 4. AgriOnt ontology [8]. 


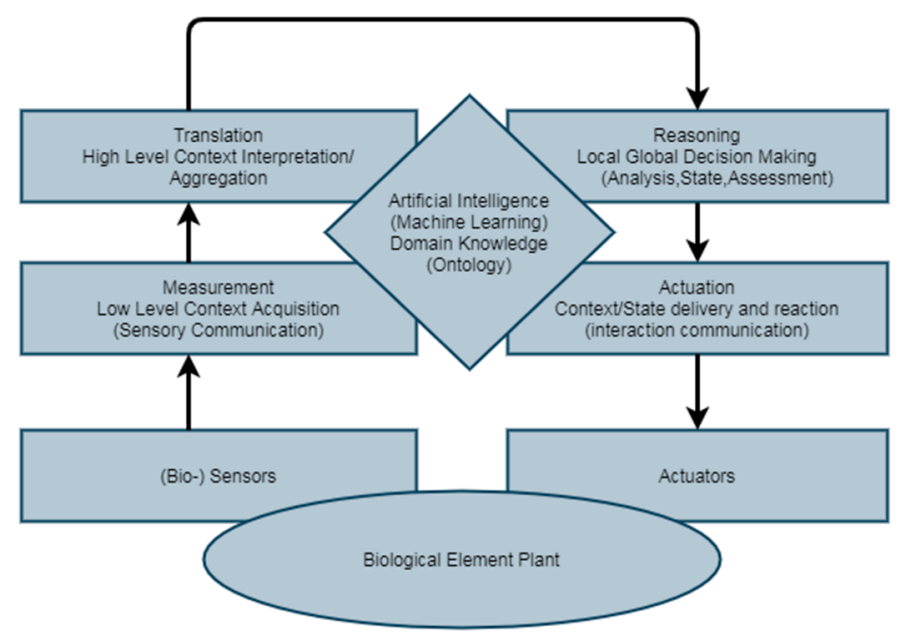

Figure 5. Plant/environmental context management process of plant [2].

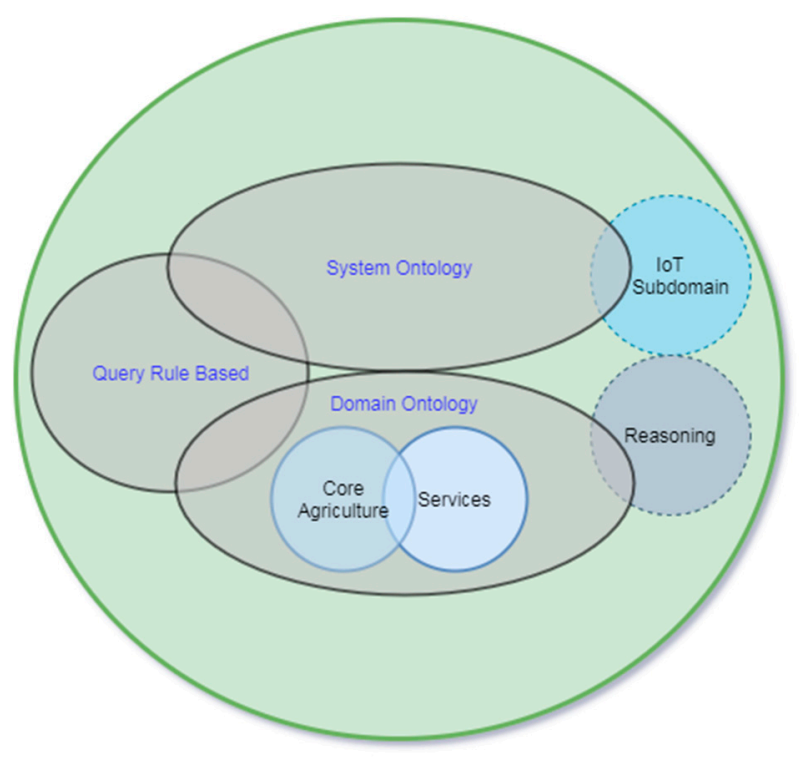

Figure 6. ONTAgriX proposed model.

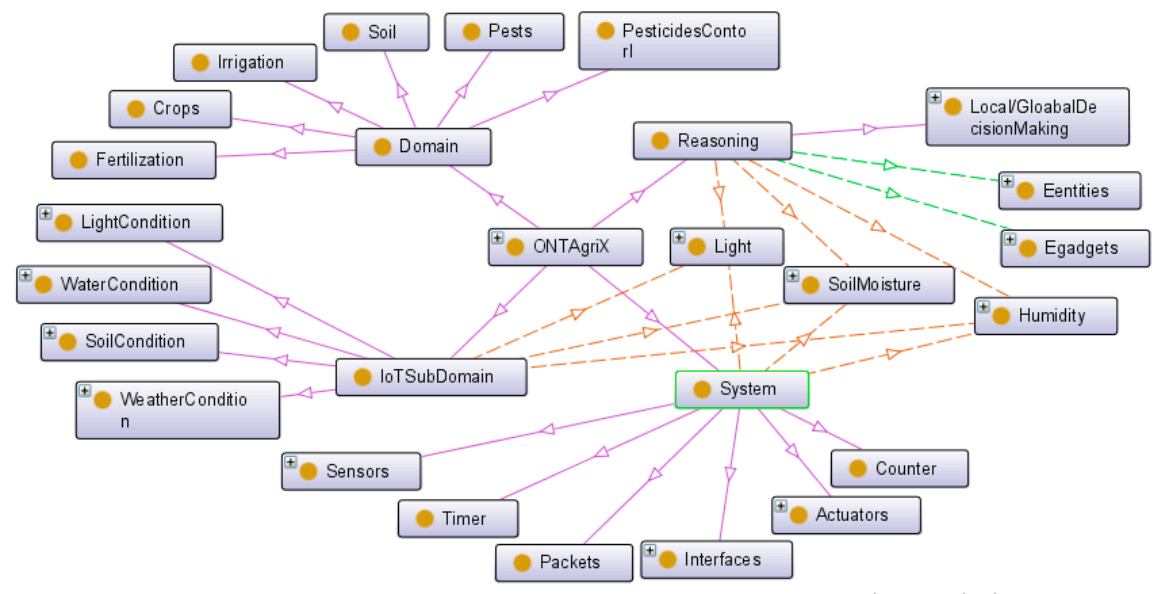

Figure 7. ONTAgriX in Protégé. 


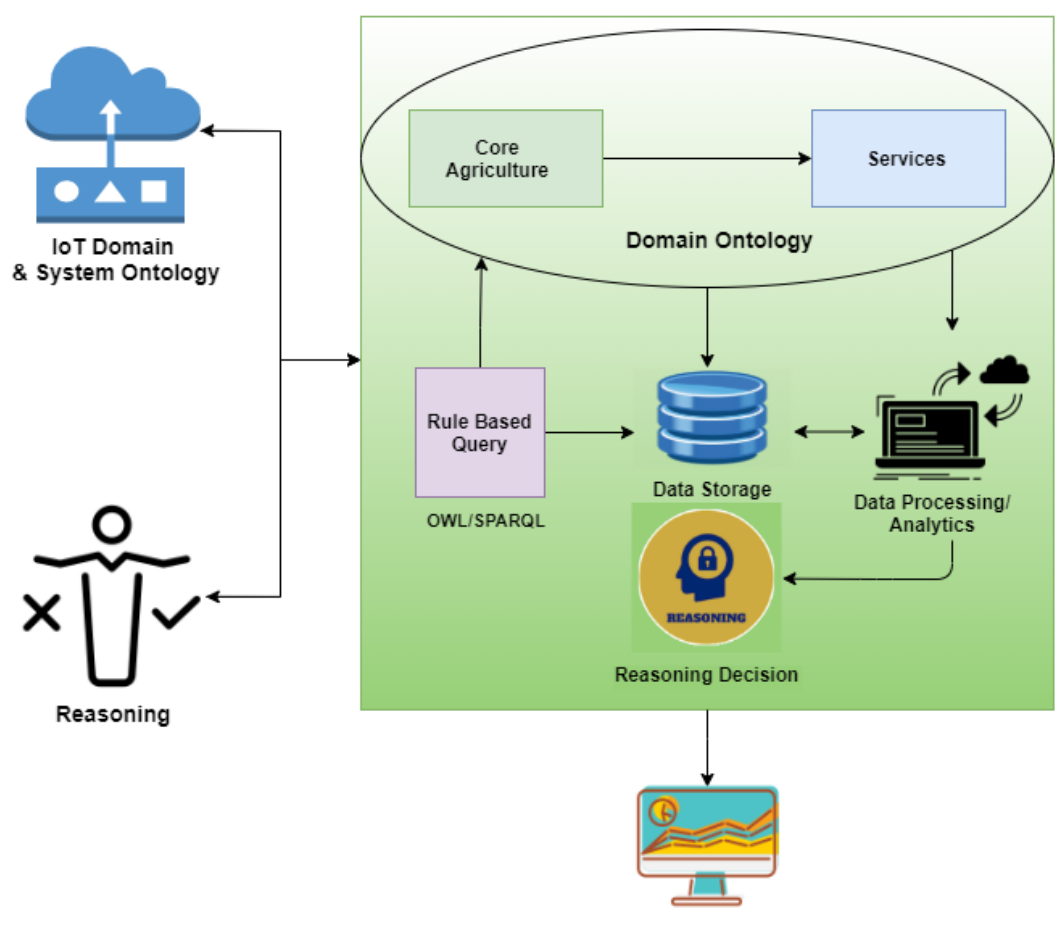

End User Visualization

Figure 8. ONTAgriX architecture.

The main data required from the plants include temperature, light, and weather conditions. The core ontology is extended by a reasoning process and IoT subdomain with reasoning decision, which shows the output to the end-user, as shown in Figure 8. The services part of ONTAgriX ontology has eIrrigation and eFertilizer, followed by the sensors and the actuators. The impacts of these eEntities are combined with respective eGadgets through global decision making.

The eFertilizer and eIrrgition are controlled through both global decision making and local decision making. Initially, the model responds to the local decision making; then, it responds to the global decision making to complete the operations selected by the farmer.

Local decision making is used on a small number of nodes. Global decision making is used in a wider context, for example, a large number of distributed nodes to communicate and exchange data. The desired system state is maintained through the combined and synchronized local and global decision-making processes [2].

The ONTAgriX is applied to precision farming by introducing new gadgets that are appropriate to match the management practices in the discipline. The purpose of these gadgets is to notify the farmers through various forms of analytics, for example, labeled videos, predication graphs, and alike. The drone technology may be present in the form of an eGadget to monitor the farm and send real-time notifications to the ground base for processing to generate desired analytics information. The alarm, as another eGadget, plays an important part in the farm to indicate the need for an action based on monitoring: for example, watering the plants, and taking care of the plants being attacked by animals and insects. The use of IoT devices can assist the farmers in locating and identifying the plants and related actions to improve productivity and ensure precision farming practices.

Figures 3-5 are the model, ontology of AgriOnt, and context management process diagrams, respectively. We have adopted the IoT subdomain, as shown in Figure 3, and the reasoning process, as shown in Figure 5. Both are included in ONTAgriX ontology.

Figure 6 is the extended version of ONTAgriX with both the IoT subdomain and reasoning. Figure 7 shows the implementation of the new model in Protégé. Figure 8 shows the architecture diagram of the proposed model. 


\section{Simulations}

Many researchers utilized Protégé in their works [1,9,24]. This work implements both ONTAgri and ONTAgriX ontologies in Protégé for precision farming applications. Figure 9 shows the Object properties and Data properties, Figure 10 shows the views available in the Individuals tab in the Protégé interface. The ONTAgriX ontology appears as the primary node in the Class hierarchy. The secondary nodes under the primary node are Reasoning, IoT subdomain, system ontology, and domain ontology. The named individuals in the Individual view are different entities. These entities include farm1, humidity sensors (HS1 and HS2Center), light sensors (LS1 and LS2Center), and soil sensors (SS1 and SS2Center). These sensors are initialized in Object Properties and Data Properties, as shown in Figure 9, and are used in the Property Assertion view, as shown in Figure 10. In Object Properties, features related to ONTAgriX are created. In Data Properties, attributes of ONTAgriX are created. In this way, data are inserted in the ONTAgriX ontology using the Data Properties assertion view and linked with different nodes.

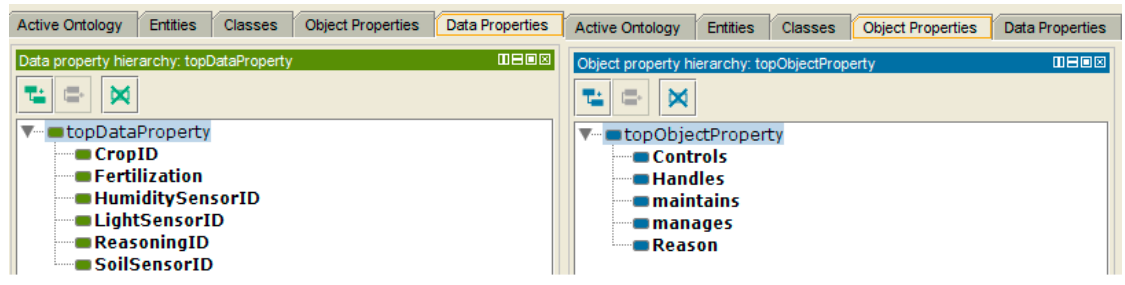

Figure 9. Object and Data Properties.

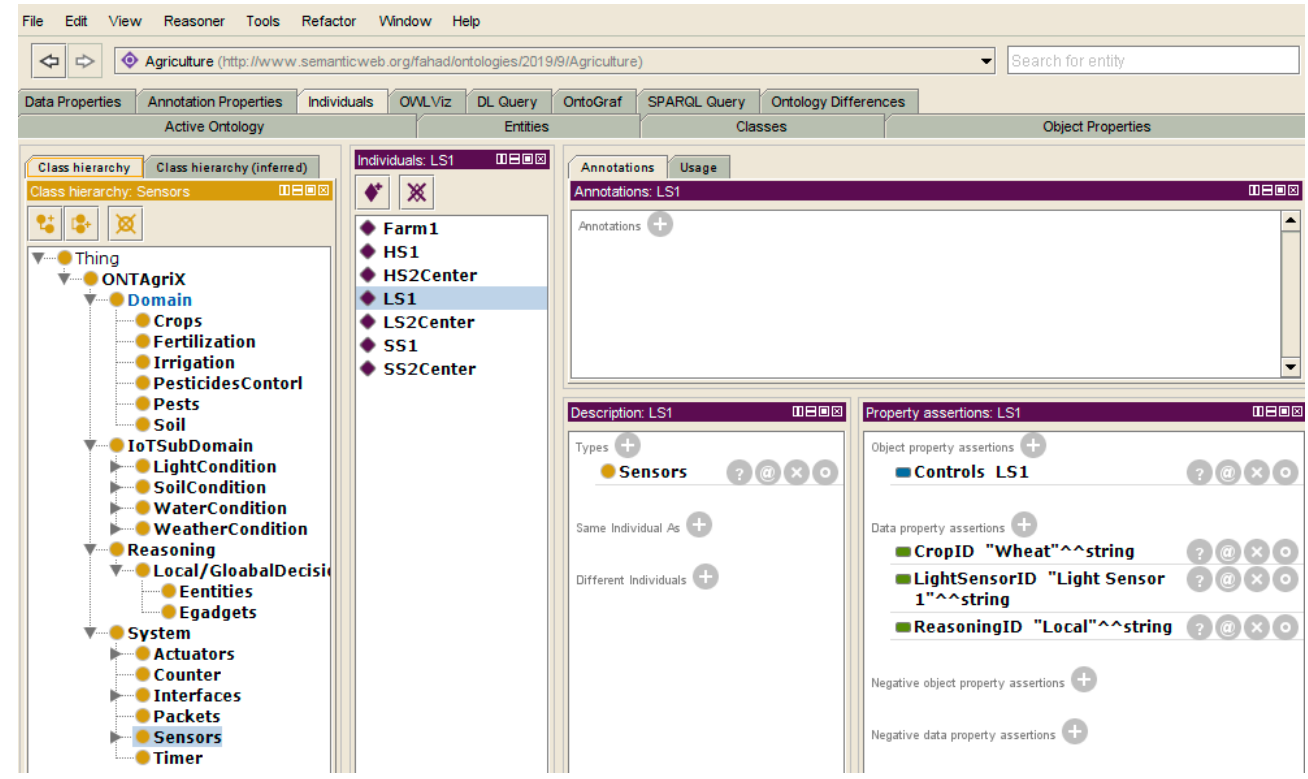

Figure 10. Individuals of ontology.

After implementation in Protégé, the data are entered in the model, synchronized with the reasoner, and the dataset is added to Jena. The SPARQL queries are used to retrieve data, as shown in Figure 11. All data are available in subject-predicate and object. According to the end-user need and requirement, data can be gathered using the data properties and object properties mentioned in Figure 9. 


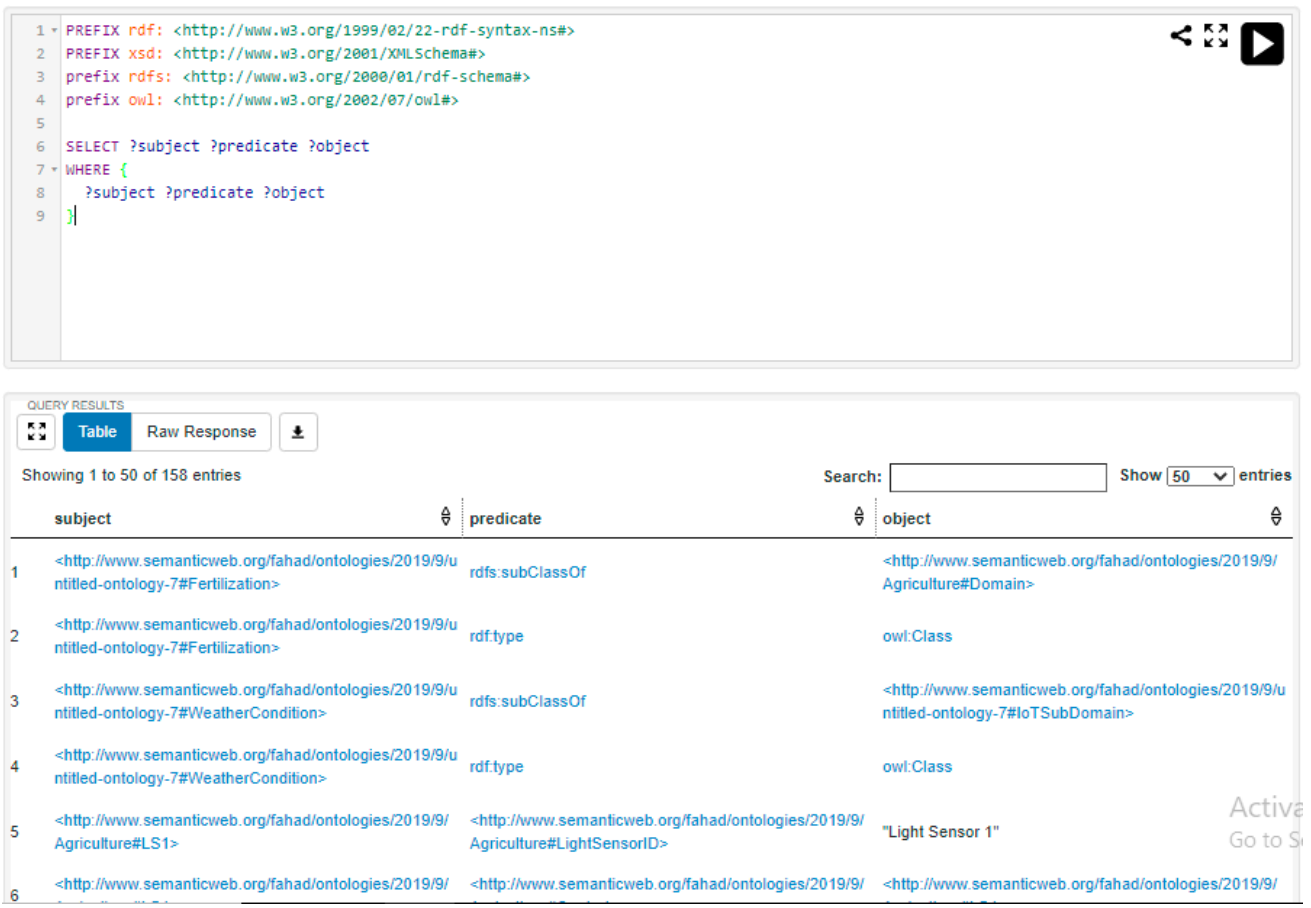

Figure 11. Generating results from Jena using SPARQL query.

\section{Results and Discussion}

The proposed new ONTAgriX ontology in this work extends ONTAgri [1] and incorporates context-awareness, scalability, and service-oriented aspects. These features were not available in the earlier proposed works on agriculture ontologies, ONTAgri [1] and AgriOnt [8]. There was no implementation described by the authors in their proposed ONTAgri [1] ontology. This work accomplished the implementation of ONTAgri to obtain a better understanding. In addition to extending the ONTAgri, this work shows the application of ONTAgriX ontology in precision farming. ONTAgriX can be implemented in any region of the land where the agriculture process exists. Since ONTAgriX is a scalable, service-oriented, and context-aware architecture, it works as a middleware between farmers and agriculture issues raised in the field, which fulfills the requirements of contextawareness [25]. It can accommodate and involve different types of input from farmers according to the region. The basic infrastructure of ONTAgriX is based on ONTAgri [1] infrastructure.

The ONTAgriX has system ontology, domain ontology, IoT subdomain, and reasoning process. In the implementation, the system ontology has light sources, sensors, plants, and actuators. The domain ontology has different group's irrigation, fertilization, etc. The IoT subdomain has numerous sensors. The reasoning process spans both local decision making and global decision making. The precision farming applications use smartphones, alarms, and drones for better results and notify the farmers. Farmers use smartphones to receive notifications and decision-support information. In case of immediate attention, alarms are used. Drones are used for real-time monitoring.

The application of ONTAgriX is designed to adjust the light intensity of the lamp. The desired optimal state of energy at the plants is ensured. The decision making process receives sensor data, performs analytics task, and suggests actions to the farmer. Based on the selected action, the actuators implement the desired action to achieve the optimal state of energy at the plants. The real-time monitoring and notifications indicate the scalability and service-oriented components of the proposed ontology. The use of precision farming applications ensures the best practices to manage the farm.

In AgriOnt ontology, the applications are built using a semantic framework. Crops, farmers, farms, diseases, affected aspects, etc., are used to relate the products with linked 
data; however, the important features of context awareness, scalability, and service-oriented are lacking. In [20], the authors demonstrated an application called pest control ontology. Their developed ontology is used in this application that supports decision control systems; however, their proposed ontology lacks service-oriented, context-awareness, and scalability features.

\section{Conclusions}

Precision farming has become immense potential in the agriculture domain with the connection of service-oriented architecture services. There is a persistent need for new techniques that will be used in the processing of raw data and extract useful information. This is especially true for the agriculture discipline. There are important disciplines, including IoT-based companies, the automation industry, businesses, and many more, that rely on useful data extraction, despite the fact that the data are continuously changing day by day. Ontology is one of the best techniques to extract related information through relations from the data. There are different usages for ontology: it can be used for a decision support system, expert system, reusability of domain knowledge, etc. Many authors develop knowledgebase systems based on an ontology which includes Plants ontology, SAAONT, AgriOnt, OntoAgroHidro, etc. In this work, a new ontology is proposed by extending an earlier ontology with additional features. The extended ontology ONTAgriX includes the features of scalability, being service-oriented, and context-awareness. Additionally, it incorporated the IoT subdomain and reasoning process for precision farming applications. The proposed architecture is modeled, implemented, and demonstrated using well-known open-source platforms. The example of the precision farming practice is described in detail. The new features, technology components, and reasoning process in the proposed ontology enable more agriculture business applications.

Author Contributions: All authors contributed to this article according to their expertise. All authors have read and agreed to the published version of the manuscript.

Funding: This research received no external funding.

Institutional Review Board Statement: Not applicable.

Informed Consent Statement: Not applicable.

Data Availability Statement: Data are not available publically, though the data may be made available on request from the corresponding author.

Conflicts of Interest: The authors declare no conflict of interest.

\section{References}

1. Rehman, A.U.; Shaikh, Z.A. ONTAgri: Scalable service-oriented agriculture ontology for precision farming. In Proceedings of the International Conference on Agricultural and Biosystems Engineering, Amsterdam, The Netherlands, 13-15 July 2011.

2. Goumopoulos, C.; Kameas, A.D.; Cassells, A. An ontology-driven system architecture for precision agriculture applications. Int. J. Metadata Semant. Ontol. 2009, 4, 72. [CrossRef]

3. Protégé. Available online: http:/ / protege.stanford.edu/ (accessed on 5 April 2012).

4. Apache Jena. Available online: https://jena.apache.org (accessed on 1 July 2021).

5. Gruber, T.R. Toward principles for the design of ontologies used for knowledge sharing? Int. J. Hum. Comput. Stud. 1995, 43, 907-928. [CrossRef]

6. Tom, G. Ontology. In Encyclopedia of Database Systems; Tamer, M.O., Ling, L., Eds.; Springer: Boston, MA, USA, 2009; Volume 6, pp. 1963-1965.

7. Tudorache, T. Ontology engineering: Current state, challenges, and future directions. Semant. Web 2020, 11, 125-138. [CrossRef]

8. Ngo, Q.H.; Le-Khac, N.A.; Kechadi, T. Ontology based approach for precision agriculture. In Proceedings of the International Conference on Multidisciplinary Trends in Artificial Intelligence, Hanoi, Vietnam, 18-20 November 2018; Manasawee, K., Rainer, M., Duc, D.N., Nicolas, S., Eds.; Springer: Cham, Switzerland, 2018; pp. 175-186.

9. Goldstein, A.; Fink, L.; Ravid, G. A Framework for Evaluating Agricultural Ontologies. Sustainability 2021, 13, 6387. [CrossRef]

10. Alreshidi, E. SAAONT: Ontological knowledge-based development to support intelligent decision-making systems for Saudi Arabian agriculture. Int. J. Adv. Appl. Sci. 2020, 7, 49-59. [CrossRef] 
11. Mazon-Olivo, B.; Hernández-Rojas, D.; Maza-Salinas, J.; Pan, A. Rules engine and complex event processor in the context of internet of things for precision agriculture. Comput. Electron. Agric. 2018, 154, 347-360. [CrossRef]

12. Taşkin, D.; Yazar, S. A Long-range Context-aware Platform Design for Rural Monitoring with IoT in Precision Agriculture. Int. J. Comput. Commun. Control. 2020, 15. [CrossRef]

13. Symeonaki, E.; Arvanitis, K.; Piromalis, D. A Context-Aware Middleware Cloud Approach for Integrating Precision Farming Facilities into the IoT toward Agriculture 4.0. Appl. Sci. 2020, 10, 813. [CrossRef]

14. Jin, X.-B.; Yu, X.-H.; Wang, X.-Y.; Bai, Y.-T.; Su, T.-L.; Kong, J.-L. Deep Learning Predictor for Sustainable Precision Agriculture Based on Internet of Things System. Sustainability 2020, 12, 1433. [CrossRef]

15. Aydin, S.; Aydin, M.N. Semantic and Syntactic Interoperability for Agricultural Open-Data Platforms in the Context of IoT Using Crop-Specific Trait Ontologies. Appl. Sci. 2020, 10, 4460. [CrossRef]

16. Feng, X.; Yan, F.; Liu, X. Study of Wireless Communication Technologies on Internet of Things for Precision Agriculture. Wirel. Pers. Commun. 2019, 108, 1785-1802. [CrossRef]

17. Vuran, M.C.; Salam, A.; Wong, R.; Irmak, S. Internet of underground things in precision agriculture: Architecture and technology aspects. Ad Hoc Netw. 2018, 81, 160-173. [CrossRef]

18. Bonacin, R.; Nabuco, O.F.; Junior, I.P. Ontology models of the impacts of agriculture and climate changes on water resources: Scenarios on interoperability and information recovery. Futur. Gener. Comput. Syst. 2016, 54, 423-434. [CrossRef]

19. Lacasta, J.; Lopez-Pellicer, F.J.; Espejo-García, B.; Nogueras-Iso, J.; Zarazaga-Soria, F.J. Agricultural recommendation system for crop protection. Comput. Electron. Agric. 2018, 152, 82-89. [CrossRef]

20. Li, D.; Kang, L.; Cheng, X.; Li, D.; Ji, L.; Wang, K.; Chen, Y. An ontology-based knowledge representation and implement method for crop cultivation standard. Math. Comput. Model. 2013, 58, 466-473. [CrossRef]

21. Bangkhomned, W.; Payakpate, J. Applying Ontology Knowledge Representation Technology and Semantic Searching Methods to Support the Production of High Quality Longan Fruit. In Information Science and Applications; Springer: Singapore, 2020; pp. 601-612. [CrossRef]

22. Alshinina, R.; Elleithy, K. Performance and Challenges of Service-Oriented Architecture for Wireless Sensor Networks. Sensors 2017, 17, 536. [CrossRef] [PubMed]

23. Vecchio, Y.; Agnusdei, G.P.; Miglietta, P.P.; Capitanio, F. Adoption of precision farming tools: The case of Italian farmers. Int. J. Environ. Res. Public Health 2020, 17, 869. [CrossRef] [PubMed]

24. Kocian, A.; Incrocci, L. Learning from Data to Optimize Control in Precision Farming. Stats 2020, 3, 239-245. [CrossRef]

25. Li, X.; Eckert, M.; Martinez, J.-F.; Rubio, G. Context Aware Middleware Architectures: Survey and Challenges. Sensors 2015, 15, 20570-20607. [CrossRef] [PubMed] 